\title{
Mucosal characteristics of pelvic ileal pouches
}

\author{
H J de Silva, P R Millard, M Kettlewell, N J Mortensen, C Prince, D P Jewell
}

\begin{abstract}
This study aimed to investigate the degree of colonic metaplasia in ileo - anal pouches. Biopsy specimens from 25 patients with functioning pouches, eight of whom had pouchitis, were studied using routine histology, mucosal morphometry, mucin histochemistry, and immunoperoxidase staining with monoclonal antibodies directed towards a $40 \mathrm{kD}$ colonic protein and a small bowel specific disaccharidase-sucrase isomaltase. Thirteen patients (including all eight with pouchitis) had subtotal or total villous atrophy and crypt hyperplasia. In this group, nine had colorectal type sulphomucin and the $40 \mathrm{kD}$ colonic protein was detected in two. These changes were not observed in patients with less severe villous abnormalities. Sucrase-isomaltase activity was, however, present in all 25 pouch specimens. We conclude that although some ileal pouches acquire certain colonic characteristics, complete colonic metaplasia does not occur.
\end{abstract}

Restorative proctocolectomy with ileal pouch anal anastomosis is now an established alternative to proctocolectomy with an end ileostomy in the surgical management of ulcerative colitis and familial adenomatous polyposis. It has also been used in other diseases limited to the colon such as Hirschprung's disease $\mathrm{e}^{2}$ and idiopathic constipation. ${ }^{3}$ As experience with this technique has grown, it has become evident that a syndrome of clinically apparent acute pouch inflammation, termed pouchitis, is becoming a major longterm complication. ${ }^{45}$ In most large series the incidence of pouchitis is between $10-20 \%{ }^{6-9}$ but it seems to occur only in patients with previous ulcerative colitis, and unequivocal pouchitis has not been reported in other patients. ${ }^{2-13}$

The cause of pouchitis is unknown. Faecal stasis and reduced volatile short chain fatty acid concentrations in pouch stool, , $14^{15}$ both of which may allow the overgrowth of toxin producing bacteria, ${ }^{416}$ have been suggested as possible mechanisms. Another hypothesis is that the pouch mucosa, in an adaptive response to its new luminal environment, undergoes colonic metaplasia $^{2+10}{ }^{16-18}$ and thus may become vulnerable to immune damage in predisposed people. ${ }^{2418}$

There has been some evidence that the pouch mucosa undergoes colonic metaplasia. Histologically, the ileal pouch mucosa may undergo a change from the villous structure of small bowel mucosa to a glandular morphology typical of colon. ${ }^{261017}$ It has also been found that in about $50 \%$ of patients, pouch mucin changes histochemically from small bowel type sialomucin to colorectal type sulphomucin. ${ }^{2}$ Both histological and histochemical changes have been seen irrespective of the original diagnosis of ulcerative colitis or familial adenomatous polyposis, ${ }^{2}$ and similar findings have been reported from intraabdominal (Kock) ileal pouches. ${ }^{19}$ Furthermore, there have been a number of reports of adenomatous polyps occurring de novo in pouches of patients who had familial adenomatous polyposis, ${ }^{2}{ }^{18} 20$ but these polyps did not develop in the ileum proximal to the pouch. ${ }^{1820}$

In previous studies, colonic metaplasia in ileal pouches has been defined in terms of histological appearances and mucin type only. The aim of this study was to determine the degree of colonic metaplasia, not only by histological and histochemical methods but also by immunohistochemical techniques, to investigate the expression of colonic antigen(s), and to assess small bowel specific disaccharidase activity in the pouch mucosa.

\section{Methods}

\section{PATIENTS AND TISSUES}

The study was approved by the Oxfordshire Health Authority Ethical Committee and informed consent was obtained from all patients.

Mucosal biopsy specimens obtained from pelvic ileal pouches of 25 patients ( 17 men, eight women, median age 29 years (range 18-56)) were studied. Twenty two originally had ulcerative colitis and three had familial adenomatous polyposis. Eight of the patients had pouchitis at the time of biopsy. Pouchitis was defined as the occurrence of bloody diarrhoea, with pouch inflammation seen on endoscopy, ${ }^{45}$ and the absence of specific pathogenic organisms in the pouch stool. The pouches had been functioning for a median of 27.5 months (range 8-68), and none of the patients were on any medication at the time of investigation, apart from occasional antidiarrhoeal drugs.

Two endoscopic biopsy specimens were obtained from adjacent areas of the pouch mucosa, at least $10 \mathrm{~cm}$ from the anal verge. Normal ileal mucosa was obtained either at colonoscopy or from surgically resected specimens at least $5 \mathrm{~cm}$ distant from the tumour. Sigmoidoscopic rectal biopsy specimens were taken from four patients with the irritable bowel syndrome (histologically normal), and four patients with active ulcerative colitis. One tissue specimen each from pouches and control tissue was fixed in buffered formalin and then embedded in paraffin. The other was immediately snap frozen in isopentane in liquid nitrogen and stored in liquid nitrogen until sectioning.

HISTOLOGY, MUCOSAL MORPHOMETRY, AND MUCIN HISTOCHEMISTRY

Four micron sections of formalin fixed paraffin embedded tissue were stained haematoxylin and \\ 19 February 1990
}


eosin (H\&E) for histology and mucosal morphometry, and with high iron diamine - alcian blue (HID-AB) for mucin histochemistry. For the latter, ferric chloride at a $60 \%$ concentration was used, ${ }^{2}$ in a modification of the method described by Spicer. ${ }^{21}$ HID-AB stains small bowel type sialomucin blue, indicating the presence of sialic acid, and colorectal type sulphomucin brown, indicating the high degree of sulphation. The stained sections were assessed for blue predominance, a mixed pattern or brown predominance. ${ }^{2}$

The H\&E sections were graded for the degree of villous atrophy (none, minor villous abnormality, partial and subtotal or total) and scored on a scale of 0 (absent) to 3 (severe) for the degree of crypt hyperplasia and acute and chronic inflammation. Mucosal morphometry (linear measurements) was performed using a calibrated eye piece (Leitz), at a magnification of $\times 100$. Linear measurements are easy to make and have been found to correlate very well with other more complex morphometric methods. ${ }^{22}$ For each section, at least five measurements of total mucosal thickness (TMT) and crypt depth (CD) were made, as described previously. ${ }^{22}{ }^{23}$ Villous height ( $\mathrm{VH}$ ) and an index of villous atrophy (VH/TMT) were then calculated. ${ }^{1622}$

\section{IMMUNOPEROXIDASE STAINING}

Monoclonal antibodies. $7 \mathrm{E}_{12} \mathrm{H}_{12}$ (provided by Dr K M Das, Robert Wood Johnson Medical School, New Brunswick, NJ) an IgM mouse anti-human monoclonal antibody, detects a $40 \mathrm{kD}$ protein which is specific to colonic and bile duct epithelium and epidermis. ${ }^{24} 25$ This antigen is not present in small bowel epithelium. ${ }^{24}$

The anti-sucrase-isomaltase antibody HBB2/ 614/88 (provided by Dr H-P Hauri, University of Basel, Switzerland) is an IgG 1, mouse antihuman monoclonal antibody. ${ }^{26}$ It is directed towards the sucrase subunit ${ }^{27}$ of this enzyme, which is specific to the small intestinal brush border. ${ }^{26-28}$

STAINING TECHNIQUE

To investigate the expression of the $40 \mathrm{kD}$ protein $4 \mu$ sections of formalin fixed paraffin embedded tissue ${ }^{24}$ were stained using a two stage immunoperoxidase technique. The sections were first deparaffinised and incubated for $\mathbf{3 0}$ minutes in $0.1 \mathrm{M}$ phosphate buffered saline (PBS) pH $7 \cdot 3$, containing $0 \cdot 3 \%$ hydrogen peroxide $\left(\mathrm{H}_{2} \mathrm{O}_{2}\right)$ to block endogenous peroxidase activity. After washing with PBS, sections were incubated for one hour with $10 \%$ normal swine serum to block non-specific binding. At the end of this incubation, excess serum was wiped from around the sections and the sections incubated overnight at $4^{\circ} \mathrm{C}$, with a one in 10 dilution of $7 \mathrm{E}_{12} \mathrm{H}_{12}$ in a humid covered chamber. After washing with $\mathrm{PBS}$, sections were then incubated for one hour with peroxidase conjugated rabbit anti-mouse immunoglobulin (Dako) as a $1 \%$ solution in PBS. After another wash, the peroxidase reaction was developed with diaminobenzidine $(0.6 \mathrm{mg} / \mathrm{ml})$ and $\mathrm{H}_{2} \mathrm{O}_{2}(0.01 \%)$. Other than for the overnight incubation, all incubations were done at room temperature. The sections were then washed in tap water, counterstained with haematoxylin, dehydrated, and mounted in DPX for light microscopy. They were graded from negative $(0)$ to strongly positive $(+++)$, for expression of the $40 \mathrm{kD}$ protein.

To detect sucrase-isomaltase activity, $5 \mu$ cryostat sections of tissue stored in liquid nitrogen, were first fixed in acetone for 10 minutes. Endogenous peroxidase activity and non-specific binding were blocked as described above and the sections were incubated with a one in 250 dilution of HBB2/614/88 for one hour at room temperature. They were then incubated with a $1 \%$ solution of peroxidase conjugated rabbit antimouse immunoglobulin (Dako) for one hour and the reaction was developed as above. Sucraseisomaltase activity on the surface epithelium and crypts was graded from negative (0) to strongly positive $(+++)$.

In all immunoperoxidase staining procedures, one serial section from each specimen was incubated with PBS alone or an unrelated monoclonal antibody as a negative control. Normal ileum, normal or inflamed colon were used as controls where appropriate. All sections $(H \& E$, HID-AB, and immunoperoxidase) were assessed without knowledge of the clinical diagnosis.

STATISTICAL ANALYSIS

Grouped data were expressed as median and range. Differences between measurements were assessed by the Mann-Whitney U-test. The significance of correlation was determined by the Spearman Rank correlation test. Statistical significance was taken as $\mathrm{p}<0.05$.

\section{Results}

Biopsy specimens obtained from pouches showed varying degrees of villous atrophy, crypt hyperplasia, and mucosal inflammation. Details of the morphometric analysis are shown in Table I. The index of villous atrophy (VH/TMT) was significantly lower (indicating a greater degree of villous atrophy) in pouches with pouchitis, compared with those without $(\mathrm{p}<0.007)$ and in pouches without pouchitis when compared with normal ileal controls $(p<0.003)$. Villous height was significantly lower and crypt depth significantly greater in

TABLE I Ileal mucosal morphometry (values given as median (range) in $\mu$ )

\begin{tabular}{|c|c|c|c|c|}
\hline & \multicolumn{2}{|c|}{$\begin{array}{l}\text { Normal ileum } \\
(N I)(n=10)\end{array}$} & $\begin{array}{l}\text { Pouches } \\
\text { without } \\
\text { pouchitis } \\
(N P)(n=17)\end{array}$ & $\begin{array}{l}\text { Pouches with } \\
\text { pouchitis } \\
(P)(n=8)\end{array}$ \\
\hline $\begin{array}{l}\text { Villous height } \\
\text { (VH) } \\
\text { Crypt depth } \\
\text { (CD) } \\
\text { Total mucosal } \\
\text { thickness (TMT) } \\
\text { VH/TMT }\end{array}$ & $\begin{array}{c}268 \\
(225- \\
162 \\
(125- \\
427 \\
(365- \\
0.63 \\
(0.56-\end{array}$ & & $\begin{array}{l}171 \\
(0-325) \\
250 \\
(109-550) \\
425 \\
(288-700) \\
0 \cdot 39 \\
(0-0.67)\end{array}$ & $\begin{array}{l}58 \\
(0-130) \\
419 \\
(294-488) \\
483 \\
(334-538) \\
0 \cdot 12 \\
(0-0 \cdot 28)\end{array}$ \\
\hline \multicolumn{2}{|c|}{ Statistical significance: } & NI:NP & \multicolumn{2}{|l|}{ NP:P } \\
\hline \multicolumn{2}{|l|}{$\begin{array}{l}\text { VH } \\
\text { CD } \\
\text { VH/TMT }\end{array}$} & $\begin{array}{l}\mathrm{p}<0.002 \\
\mathrm{p}<0.02 \\
\mathrm{p}<0.003\end{array}$ & \multicolumn{2}{|c|}{$\begin{array}{l}\mathrm{p}<0.006 \\
\mathrm{p}<0.02 \\
\mathrm{p}<0.007\end{array}$} \\
\hline
\end{tabular}


TABLE II Score for mucosal inflammation

\begin{tabular}{|c|c|c|c|c|c|}
\hline \multirow{2}{*}{$\begin{array}{l}\text { Median (range) } \\
\text { score for: } \\
\text { Acute } \\
\text { inflammation } \\
\text { Chronic } \\
\text { inflammation }\end{array}$} & \multicolumn{2}{|c|}{$\begin{array}{l}\text { Normal ileum } \\
(N I)(n=10)\end{array}$} & \multicolumn{2}{|c|}{$\begin{array}{l}\text { Pouches } \\
\text { without } \\
\text { pouchitis } \\
(N P)(n=17)\end{array}$} & $\begin{array}{l}\text { Pouches with } \\
\text { pouchitis } \\
(P)(n=8)\end{array}$ \\
\hline & $\begin{array}{c}0 \\
(0) \\
0 \\
(0-1)\end{array}$ & & $\begin{array}{l}0 \\
(0-1) \\
1 \\
(0-2)\end{array}$ & & $\begin{array}{l}2 \\
(2-3) \\
3 \\
(2-3)\end{array}$ \\
\hline \multicolumn{2}{|c|}{ Statistical significance: } & NI:NP & & NP:P & \\
\hline \multicolumn{2}{|c|}{$\begin{array}{l}\text { Acute inflammation } \\
\text { Chronic inflammation } \\
\text { VH/TMT }\end{array}$} & $\begin{array}{l}\mathrm{p}<0.05 \\
\mathrm{p}<0.001 \\
\mathrm{p}<0.003\end{array}$ & & \multicolumn{2}{|c|}{$\begin{array}{l}\mathrm{p}<0.001 \\
\mathrm{p}<0.001 \\
\mathrm{p}<0.007\end{array}$} \\
\hline
\end{tabular}

Score: 0 =absent, $1=$ mild, $2=$ moderate, $3=$ severe

pouches with pouchitis compared with pouches without, and in pouches without pouchitis when compared to normal ileum. Some pouches without pouchitis had indices of villous atrophy similar to those seen in pouchitis. There was, however, no significant difference in total mucosal thickness between the three groups, indicating that villous atrophy was inversely related to crypt depth.

Of the biopsy specimens from 25 pouches studied, 13 showed subtotal or total villous atrophy and crypt hyperplasia, and resembled colonic mucosa histologically. These included the eight patients with pouchitis, all of whom had originally had ulcerative colitis. Histologically, patients with pouchitis had prominent acute inflammatory changes with a moderate to severe degree of polymorphonuclear neutrophil infiltration which was at times associated with crypt abscess formation and mucosal ulceration. Most pouches without pouchitis had only a mild degree of chronic inflammation. Patients with pouchitis had significantly higher scores for acute and chronic inflammation when compared with patients with pouches but no pouchitis (Table II). Patients with pouches but no pouchitis had scores of inflammation that were significantly higher when compared to those of normal ileum. There was no correlation between indices of villous atrophy and scores for mucosal inflammation.

There was a significant inverse correlation between the index of villous atrophy (VH/TMT) and the amount of colorectal type sulphomucin present in the pouch mucosa $\left(r_{s}=-0.628\right.$, $\mathrm{p}<0.002$ ) such that, sulphomucin was detected predominantly in the biopsy specimens with subtotal or total villous atrophy (Fig 1, Table III). However, four of the eight patients with pouchitis had predominantly sialomucin. A mixed pattern of mucin staining was seen in two biopsy specimens from patients with partial villous atrophy. In pouches with only minor villous abnormalities and in the ileal controls there was predominantly sialomucin. The four normal colons had predominant sulphomucin, but this changed to a mixed pattern in the four with active ulcerative colitis. In pouches, the histological changes and change in mucin to sulphomucin occurred irrespective of the original diagnosis.

The $40 \mathrm{kD}$ protein was detected in only two biopsy specimens both with subtotal or total villous atrophy and sulphomucin predominance. Neither patient had pouchitis. One originally

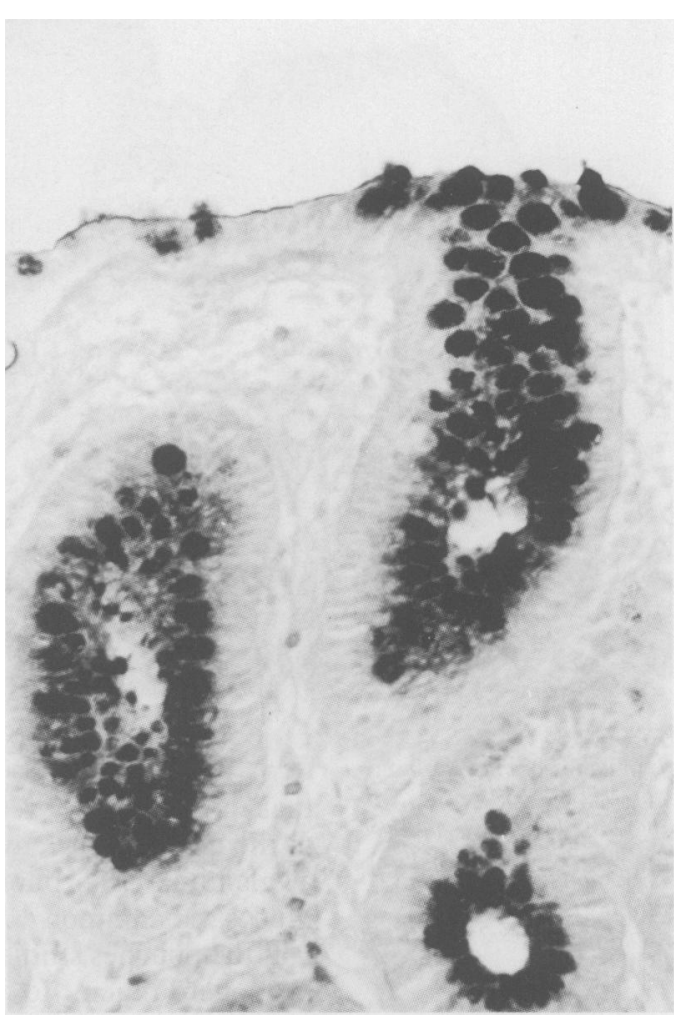

Figure 1: Mucin histochemistry of pouch mucosa with subtotal/total villous atrophy and crypt hyperplasia, showing the predominance of dark brown staining goblet cells containing colorectal type sulphomucin (original magnification $\times 400)$.

had ulcerative colitis and the other familial adenomatous polyposis. The expression of the antigen was weak $(+)$ and patchy, when compared with its strong expression $(+++)$ in normal colon. The immunoreactivity, however, was similar to that in colon, namely along the baso-lateral areas of the surface and crypt epithelial cells. ${ }^{24}$ The $40 \mathrm{kD}$ protein was not detected in normal ileal controls and its expression was greatly attenuated ( + and patchy) in the biopsy specimens from the four patients with active ulcerative colitis.

Sucrase-isomaltase activity was detected in all 25 pouch specimens. Its expression was strong $(+++)$ on the surface epithelium and weaker $(+$ or ++$)$ in the crypts, and was present mainly on the luminal surface of the cells. This pattern of expression, which was similar to that in the normal ileal controls, did not vary either with the degree of villous atrophy or inflammation (Fig 2). There was no enzyme activity in normal or inflamed colons.

\section{Discussion}

Several studies have shown that the ileal pouch mucosa undergoes morphological changes $2+61217$

TABLE III Results of mucin staining in biopsy specimens from patients with ileo-anal pouches (numbers in parentheses indicate specimens from those with pouchitis)

\begin{tabular}{llll}
\hline $\begin{array}{l}\text { Degree of villous } \\
\text { atrophy }\end{array}$ & $\begin{array}{l}\text { Predominant } \\
\text { sulphomucin }\end{array}$ & Mixed & $\begin{array}{l}\text { Predominant } \\
\text { sialomucin }\end{array}$ \\
\hline Subtotal/total & $4(1)$ & $5(3)$ & $4(4)$ \\
Partial & - & $2(0)$ & $3(0)$ \\
$\begin{array}{l}\text { Minor villous } \\
\quad \text { abnormalities }\end{array}$ & - & - & $7(0)$ \\
\hline
\end{tabular}




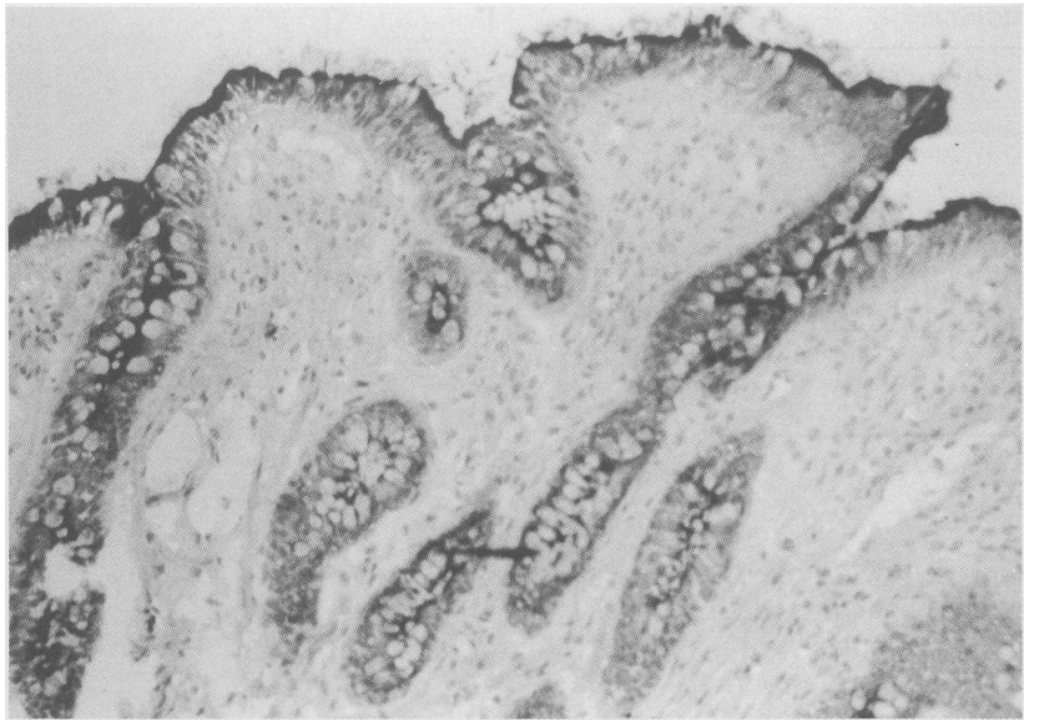

Figure 2:

Immunoperoxidase staining with $H B B 2 / 614 / 88$, showing sucrase - isomaltase activity in pouch mucosa with subtotal/total villous atrophy (original magnification $\times 250$ )

that most probably reflect an adaptive response to the new luminal environment. ${ }^{161819}$ Change to a glandular morphology resembling colonic mucosa is common ${ }^{212}$ and can occur in up to half the pouches studied. ${ }^{6}$ Histochemical change in pouch mucin to sulphomucin is seen in pouches with villous atrophy. ${ }^{2}$ These findings have led to the hypothesis that the pouch mucosa undergoes colonic metaplasia and thus it may become vulnerable to immune damage or polyp formation in predisposed people. ${ }^{2+517}$

Until now, studies have defined colonic metaplasia in pouches by means of histological changes and changes in mucin histochemistry. We believe that the definition of metaplasia should also include functional and antigenic characteristics, ${ }^{29}$ in order to hypothesise that the changes observed in the pouch mucosa make it behave like colonic mucosa. This study has investigated such characteristics in pelvic ileal pouches.

For this study, pouchitis was defined as clinical symptoms with inflammation visible at endoscopy. These pouches had a more severe degree of villous atrophy (subtotal or total villous atrophy and crypt hyperplasia) than pouches without pouchitis. We also found that pouches without pouchitis had a greater degree of villous atrophy and crypt hyperplasia than normal ileal control tissue, and that in some of these pouches the degree of villous atrophy and crypt hyperplasia was similar to that observed in the pouchitis patients, a finding reported by others. ${ }^{217}$ Our observation that there was no correlation between the degree of villous atrophy and the score for both acute and chronic mucosal inflammation has also been reported in a recent study by Nasmyth et al. ${ }^{16}$ As villous atrophy and crypt hyperplasia in pouches are associated with increased crypt cell proliferation ${ }^{1931}{ }^{31}$ (de Silva et al unpublished data), factors other than lymphokines may be important in stimulating crypt cell proliferation in pouches.

A change in pouch mucin to colorectal type sulphomucin was seen predominantly in the pouch specimens that resembled colonic mucosa histologically (subtotal/total villous atrophy and crypt hyperplasia) (Table III). Despite the presence of subtotal or total villous atrophy, however, four of the eight pouchitis specimens had predominant sialomucin. An explanation for this may be the instability of mucins in the presence of inflammation; a degree of change from sulphomucin to sialomucin is known to occur in the colon in active ulcerative colitis, ${ }^{32}{ }^{33} \mathrm{a}$ change that was observed in our ulcerative colitis control subjects. A similar change may have occurred in the four patients with pouchitis. ${ }^{2} \mathrm{~A}$ mixed mucin pattern was seen in only two of the 12 pouches with less severe villous abnormalities, and none of these had predominant sulphomucin.

The monoclonal antibody $7 \mathrm{E}_{12} \mathrm{H}_{12}$ detects a 40 $\mathrm{kD}$ protein present in colonic epithelium but not in small bowel. ${ }^{24}$ Its tissue specificity to colon and bile duct epithelium, and epidermis has been confirmed. ${ }^{2+25}$ This $40 \mathrm{kD}$ colonic antigen, was detected in two pouch specimens, both of which had subtotal or total villous atrophy and crypt hyperplasia, and sulphomucin. This antigen was not detected in any of the patients with pouchitis. We have further shown that the expression of this antigen was greatly attenuated in colonic biopsy specimens with active ulcerative colitis. It has been found that tissue bound IgG obtained from the colons of patients with active ulcerative colitis inhibits the binding of the antibody $7 \mathrm{E}_{12} \mathrm{H}_{12}$ to the $40 \mathrm{kD}$ protein ${ }^{2+}$ and it has been suggested that this antibody may play a role in the pathogenesis of this disorder. Antibody binding to the antigen may explain the attenuation of antigen expression in the colonic specimens with active ulcerative colitis and if, as suggested, the pathogenesis of pouchitis is related to that of ulcerative colitis, ${ }^{2+63+35}$ this may also explain its lack of expression in pouchitis.

Sucrase-isomaltase activity was detected in all 25 pouch specimens regardless of the degree of inflammation, degree of villous atrophy, mucin type, or expression of the $40 \mathrm{kD}$ protein. Activity was stronger in the surface epithelium, which consists of more mature cells than the crypts. This enzyme is specific to small bowel and although enzyme activity may be detected in mid-gestational fetal colon and undifferentiated colonic carcinomas, it is not present in normal or inflamed colon ${ }^{28}$ (it was not detected in our colonic controls). The finding of enzyme activity in all the pouch specimens is evidence that the pouch mucosa retains inherent small bowel characteristics and that complete colonic metaplasia does not occur. This is further supported by evidence that both pelvic and Kock pouches retain the ability to absorb $\mathrm{D}$-xylose, phenylalanine, vitamin $B_{12}$ and bile salts, ${ }^{30}{ }^{36-39}$ although a recent study ${ }^{17}$ found impairment of both xylose and bile acid absorption.

This study has confirmed that the pouch mucosa can undergo the morphological changes of subtotal or total villous atrophy and crypt hyperplasia, giving it a striking resemblance to colonic mucosa. This change was associated with pouchitis, change to colorectal type sulphomucin, and, more rarely, the expression of a 40 $\mathrm{kD}$ 'colonic' antigen. Despite these changes, however, small bowel specific disaccharidase activity persisted, this being evidence that although some pouches may acquire certain 
colonic characteristics, complete colonic metaplasia does not occur. Except for pouchitis, which occurred only in those patients with previous ulcerative colitis, all the other changes were independent of the original diagnosis and are probably an adaptive response to the new luminal environment. Although complete colonic metaplasia does not occur, the acquisition of even some colonic characteristics by the pouch mucosa may have a role in the pathogenesis of pouchitis.

H J de Silva was in receipt of a Wellcome Fellowship, and is a present in receipt of a Wingate scholarship and an Overseas Research Student award.

1 Oresland T, Fasth S, Nordgren S, Hulten L. The clinical and functional outcome after restorative proctocolectomy: A prospective study in 100 patients. Int $\mathcal{F}$ Colorect Dis 1989; 4 $50-6$.

2 Shepherd NA, Jass JR, Duval I, Moskowitz RL, Nicholls RJ Morson BC. Restorative proctocolectomy with ilea reservoir: pathological and histochemical study of mucosal biopsy specimens. I Clin Pathol 1987; 40: 601-7.

3 Pescatori M, Mattana C, Castagneto M. Clinical and functional results after restorative proctocolectomy. Brf S urg 1988; 75 ; $321-4$.

4 Tytgat GNJ, van Deventer SJH. Pouchitis. Int $\mathcal{F}$ Colorect Di 1988; 3: 226-8.

5 Scott AD, Phillips RKS. Ileitis and pouchitis after colectomy for ulcerative colitis. Br f Surg 1989; 76: 668-9.

6 O'Connell PR, Rankin DR, Weiland LH, Kelly KA. Enteric bacteriology, absorption, morphology and emptying afte ileal pouch-anal anastomosis. Br 7 Surg 1986; 73: 909-14.

7 Pemberton JH, Kelly KA, Beart RW, Dozois RR, Wolff BG Ilstrup DM. Ileal pouch - anal anastomosis for chronic ulstrup DM. Ileal pouch - anal anastomosis for

8 Taylor BA, Dozois RR. The J ileal pouch-anal anastomosis. World f Surg 1987; 11: 727-34.

9 Fleshman JW, Cohen Z, McLeod RS, Stern H, Blair J. The ileal reservoir and ileoanal anastomosis procedure: Factors affecting technical and functional outcome. Dis Colon Rectum 1988; 31: 10-16.

10 Nicholls RJ, Belliveau P, Neill M, Wilks M, Tabaqchali S Restorative proctocolectomy with ileal reservoir: a pathophysiological assessment. Gut 1981; 22: 462-8.

11 Dozois RR, Goldberg SM, Rothenberger DA, et al. Restorative proctocolectomy with ileal reservoir. Int $f$ Colorect Dis 1986; 1: 2-19

12 Moskowitz RL, Shepherd NA, Nicholls RJ. An assessment of inflammation in the reservoir after restorative proctocolectomy with ileoanal ileal reservoir. Int 7 Colorect $D$ is 1986; 1: $167-74$.

13 Heimann TM, Gelernt I, Salky B, Bauer J, Greenstein A, Beck AR. Familial polyposis coli: Results of Mucosal Proctec tomy with ileoanal anastomosis. Dis Colon Rectum 1987, 30(6): 424-7.

14 Fonkalsrud EW. Endorectal ileoanal anastomosis with isoperistaltic ileal reservoir after colectomy and mucosal proctectomy. Ann Surg 1984; 199: 151-7.

15 Ambroze WL, Pemberton JH, Bell AM. Haddad AC, Phillips SF. Fecal short chain fatty acids after ileal pouch-anal anastomosis Gastroemterology 1989; $96(5)$; All (abstract).

16 Nasmyth DG, Godwin PGR, Dixon MF, Williams NS Johnston D. Ileal ecology after pouch - anal anastomosis or ileostomy: A study of mucosal morphology, fecal bacteriology, fecal volatile fatty acids, and their interrelationteriology, fecal volatile fatty acids, and

17 Lerch MM, Braun J, Harder M, Hofstadter F, Schumpelick $\mathrm{V}$, Matern S. Postoperative adaptation of the small intestin after total colectomy and J-pouch-anal anastomosis. $D$ Colon Rectum 1989; 32(7): 600-8.
18 Wolfstein IH, Bat L, Neumann G. Regeneraton of recta mucosa and recurrent polyposis coli after total colectomy and ileoanal anastomosis. Arch Surg 1982; 117: 1241-2.

19 Go PMNYH, Lens J, Bosman FT. Mucosal alterations in the reservoir of patients with Kock's continent ileostomy. Scand f Gastroenterol 1987; 22: 1076-80.

20 Stryker SJ, Carney JA, Dozois RR. Multiple adenomatous polyps arising in a continent reservoir ileostomy. Int $\mathcal{f}$ Colorect Dis 1987; 2: 43-5.

21 Spicer SS. Diamine methods for differentiating mucosub stances histochemically. $\mathcal{F}$ Histochem Cytochem 1965 13(3): 211-33.

22 Corazza GR, Frazzoni M, Dixon MF, Gasbarrini G. Quantitative assessment of the mucosal architecture of jejunal biopsy specimens: a comparison between linear measurement, stereology, and computer aided microscopy. $\mathcal{F}$ Clin Pathol 1985; 38: 765-70.

23 Scott BB, Losowsky MS. Patchiness and duodenal-jejuna variation of the mucosal abnormality in coeliac disease and dermatitis herpetiformis. Gut 1976; 17:984-92.

24 Das KM, Sakamaki S, Vecchi M, Diamond B. The production and characterization of monoclonal antibodies to a human colonic antigen associated with ulcerative colitis: Cellular localization of the antigen by using the monoclonal antibody. f Immunol 1987; 139: 77-84.

25 Vecchi M, Sakamaki S, Das KM. The Mr40,000 colonic protein, an autoantigen associated with ulcerative colitis: Recognition of a similar epitope(s) in skin and biliary tree by anti-Mr 40,000 antibodies. Gastroenterology 1987; 92: 1682 (abstract)

26 Hauri H-P, Sterchi EE, Bienz D, Fransen JAM, Marxer A Expression and intracellular transport of microvillus membrane hydrolases in human intestinal epithelial cells. $7 \mathrm{Cell}$ Biol 1985; 101: 838-51.

27 Naim HY, Roth J, Sterchi EE, Lentze M, Milla P, Schmitz J Hauri H-P. Sucrase-isomaltase deficiency in humans: Dif ferent mutations disrupt intracellular transport, processing, and function of an intestinal brush border 'enzyme. $\mathcal{F}$ Clin Invest 1988; 82: 667-79.

28 Zweibaum A, Triadou N, Kedinger M, Augeron C, RobineLeon S, Pinto M, Rousset M, Haffen K. Sucrase-isomaltase: A marker of foetal and malignant epithelial cells of the human colon. Int 7 Cancer 1983; 32: 407-12.

29 Filipe MI. Histochemistry of intestinal mucins in, Whitehead $\mathbf{R}$ (ed), Gastrointestinal and oesophageal pathology. 1st $R$ (ed), Gastrointestinal and oesophageal pat
ed London: Churchill-Livingstone, 1989; 41-9.

30 Philipson B, Brandberg A, Jagenberg R, Kock NG, Lager I Ahren C. Mucosal morphology, bacteriology, and absorp tion in intra-abdominal ileostomy reservoir. Scand $\mathcal{f}$ Gastroenterol 1975; 10: 145-53.

31 Kmiot WA, Youngs DJ, Winslet MC, Curran FT, Keighley MRB. Ileal adaptation following restorative proctocolectomy. Brf Surg 1989; 76(6): 625 (abstract).

32 Ehsanullah M, Filipe MI, Gazzard B. Mucin secretion in inflammatory bowel disease: Correlation with disease activity and dysplasia. Gut 1982; 23: 485-9.

33 Jass JR, England J, Miller K. Value of mucin histochemistry in follow up surveillance of patients with long standing in follow up surveillance of patients with long

34 Knobler H, Ligumsky M, Okon E, Ayalon A, Nesher R Rachmilewitz D. Pouch ileitis - recurrence of the inflammatory bowel disease in the ileal reservoir. Am $\mathcal{J}$ Gastromatory bowel disease in the

35 Klein K, Stenzel P, Katon P. Pouch ileitis: Report of a case with severe systemic manifestations. $\mathcal{f}$ Clin Gastroenterol 1983; 5: 149-53.

36 Jagenburg R, Kock NG, Philipson B. Vitamin $B_{12}$ absorption in patients with continent ileostomy. Scand $\mathcal{F}$ Gastroenterol 1975; 10: 141-4.

37 Gadacz TR, Kelly KA, Phillips SF. The continent ileal pouch: absorptive and motor features. Gastroenterology 1977; 72 1287-91.

38 Go PMNYH, van Dieijen-Visser MP, Davies BI, Lens J, Brombacher PJ. Microbial flora and bile acid metabolism in patients with an ileal reservoir. Scand $\mathcal{f}$ Gastroenterol 1988 ; 23: 229-36.

39 Nasmyth DG, Johnston D, Williams NS, King RFGJ, Birkinshaw L, Brooks K. Changes in the absorption of bile acids after total colectomy in patients with an ileostomy or pouch-anal anastomosis. Dis Colon Rectum 1989; 32(3): $230-4$. 